\title{
Cytomegalovirus Antigen Measurement
}

National Cancer Institute

\section{Source}

National Cancer Institute. Cytomegalovirus Antigen Measurement. NCI Thesaurus. Code C154828.

The determination of the cytomegalovirus antigen present in a sample. 